\title{
Музейное волонтерство в структуре добровольчества в сфере культуры
}

Понятие «музейный волонтер» появилось в нашей стране в последние десятилетия и требует осмысления в контексте общих тенденций усилившегося внимания государства и общества к волонтерской деятельности, проявившегося в законотворчестве, создании программ поддержки и тенденции к институциализации и профессионализации. Смысловое поле культурной практики и научного исследования обогатилось также понятиями «волонтер культуры» и «волонтер наследия», не ставшими пока предметом отдельного изучения, но отразившими происходящие процессы содержательного наполнения разноплановой добровольной деятельности в сфере культуры. В быстро меняющемся мире современности феномен волонтерства в сфере культуры подвержен динамическим изменениям, однако в качестве социально одобряемого и поддерживаемого государством и обществом явления становится платформой социального объединения и взаимодействия, развития личности и культуры.

Ключевые слова: музей, культурное наследие, волонтер, волонтеры культуры, музейные волонтеры, волонтеры наследия

\section{Julia V. Zinovjeva}

\section{Museum volunteering as a voluntary activity in the cultural sphere}

The concept of «museum volunteer» appeared in our country in recent decades and needs to be understood in the context of general trends in the increased attention of the state and society to volunteering, manifested in lawmaking, creation of support programs and trend towards institutionalization and professionalization. The semantic field of cultural practice and scientific research has also been enriched with the concepts of «volunteers for preservation of the objects of cultural and historical heritage», which have not become the subject of a separate study yet but reflected the ongoing processes of meaningful filling of diverse voluntary activities in the cultural sphere. In the rapidly changing world of our time, the phenomenon of volunteering in the field of culture is subject to dynamic changes, however, as a phenomenon socially approved and supported by the state and society, it becomes a platform for social unification and interaction, for development of personality and culture.

Keywords: museum, cultural heritage, volunteer, volunteers of culture, museum volunteers, volunteers for preservation of the objects of cultural and historical heritage

DOI 10.30725/2619-0303-2021-2-39-44

Последние годы отмечены ростом интереса к практикам и теоретическим обоснованиям волонтерской деятельности. Год волонтера, объявленный Правительством РФ в 2018 г., принятие соответствующих поправок в нормативно-правовые акты и создание новых, появление серьезных исследований и новых понятий, в том числе новых смыслов понятия «волонтер» (доброволец), которое прежде несло иные коннотации, прежде всего связанные с воинской службой. В практике и литературе широко используются понятия «волонтер культуры», «волонтер наследия» и «музейный волонтер», тогда как каждое из данных явлений и обозначающих его понятий проходит стадию становления. Задачей данной работы является уточнение и выявление соотношений данных понятий.

Понятие волонтер (доброволец) зафиксировано только в 2018 г. в Федеральном законе 11 августа 1995 г. № 135-Ф3 «О благотворительной деятельности и добровольчестве (во- лонтерстве)» (ст. 5, п. 4), благодаря поправкам, внесенным в него Федеральным законом от 5 февраля 2018 г. № 15-Ф3 «О внесении изменений в отдельные законодательные акты Российской Федерации по вопросам добровольчества (волонтерства)» [1]. Опираясь на Федеральный закон, будем в дальнейшем рассматривать понятия «доброволец» и «волонтер» в качестве синонимов, понимая относительность этого взаимозамещения и дополнительные коннотации, связанные с обоими понятиями. Волонтер (доброволец), согласно закону, - «физическое лицо, осуществляющее добровольческую (волонтерскую) деятельность в целях, указанных в Федеральном законе, или в иных общественно полезных целях» [1].

В данном законе зафиксированы цели волонтерской деятельности (ст. 2, п. 1), каждая из которых дает развитие собственному направлению добровольчества. Выделим только те, которые касаются сферы культуры и фиксируют, 
во-первых, широкие возможности деятельности волонтера в междисциплинарной сфере (наука, культура, искусство, образование, развитие), вовторых, непосредственно связаны с охраной и поддержанием функционирования объектов культурного и природного наследия:

«- содействия деятельности в сфере образования, науки, культуры, искусства, просвещения, духовному развитию личности;

- охраны и должного содержания зданий, объектов и территорий, имеющих историческое, культовое, культурное или природоохранное значение, и мест захоронения» [1, с. 5].

Распоряжение Правительства РФ от 27 декабря 2018 г. № 2950-р. «Об утверждении Концепции развития добровольчества (волонтерства) в России до 2025» отмечает уже единое поле волонтерской деятельности сфере культуры, разделяемое на несколько ведущих сегментов, но не исключающих и другие возможные: «Основными направлениями добровольчества (волонтерства) в сфере культуры являются: поддержка деятельности организаций культуры; содействие в организации и проведении массовых мероприятий в сфере культуры; участие в осуществлении работ по сохранению объектов культурного наследия (памятников истории и культуры); вовлечение деятелей культуры и искусства в добровольческую (волонтерскую) деятельность» [2].

В 2019 г. разработана и утверждена заместителями министра культуры О.С. Ярилиной и С. Г. Обрывалиным программа «Волонтеры культуры», рассчитанная на реализацию с 2019 по 2024 г. Для ее осуществления и организационно-методической поддержки на платформе Ассоциации волонтерских центров создана Дирекция общественного движения «Волонтеры культуры», запущен собственный сайт, публикуются информационно-методические материалы. Министерство культуры РФ впервые включило программу, связанную с волонтерской деятельностью, «Волонтеры культуры» в рамки федерального проекта «Творческие люди» национального проекта «Культура» [3]. Волонтерство культуры, воспринимаемое в качестве практики, нацеленной на развитие активности населения и гражданского общества в целом, было признано эффективным путем для достижения ведущей цели национального проекта - вовлечения граждан в культуру (показатель - увеличение в 2 раза). Одной из десяти задач проекта стала поддержка добровольческих движений, в том числе в сфере сохранения культурного наследия народов Российской Федерации. Основной целью программы «Волонтеры культуры» является «обеспечение поддержки добровольческих движений в сфере культуры, в том числе в сфере сохранения культурного наследия народов Российской Федерации включая деятельность по сохранению исторического облика малых городов» [3], выраженное в таком числовом показателе, как привлечение к этой работе 100000 человек к 2024 г.

Волонтерское движение было поддержано Президентом и Правительством Российской Федерации и превратилось в один из трендов государственной культурной политики, поддержанным бизнесом, общественными организациями и благотворительными фондами. Так с 2019 г. Фонд Потанина запустил самостоятельную программу «Музейный волонтер» с целью поддержки и продвижения волонтерства в музеях.

Разнообразие встречающихся понятий «волонтеры культуры», «волонтеры сферы культуры и искусства», «культурные волонтеры», «волонтеры культурного направления» рассмотрели Н. И. Горлова, Д. Т. Маковецкая в методических рекомендациях «Сборник волонтерских практик в сфере культуры» [4, с. 10-13]. Предлагаемые определения отражают преимущественно институциональный подход: «добровольцы (волонтеры) - это физические лица, осуществляющие благотворительную деятельность в учреждении культуры в форме безвозмездного труда в интересах благополучателя. К благополучателям относятся лица, получающие блага, производимые учреждением культуры, помощь добровольцев» $[4$, с. 11].

Однако обобщение практики дает основания выйти за рамки институционального подхода и предложить широкое определение понятия «волонтер культуры» - физическое лицо, осуществляющее добровольную и безвозмездную деятельность в сфере культуры. Волонтерство культуры от других волонтерских практик отличает не только особенность институционального поля деятельности и преобладающие задачи по его поддержке и продвижению.

Здесь присутствует прежде всего безусловная позитивная эмоциональная составляющая, связанная с явлениями культуры (в отличие от волонтерства социального, где приходится сталкиваться и с негативными общественными феноменами, например, неизлечимыми болезнями или социальной несправедливостью), и направленность на приобщение к культуре и развитие личности самих волонтеров.

Таким образом, в сфере волонтерства культуры на нормативно-правовом уровне закрепляются основные 4 направления, каждое из которых приводит к формированию понятий, отражающих особенности работы в каждом из них: 


\section{Музейное волонтерство в структуре добровольчества в сфере культуры}

- институциональное волонтерство (в том числе музейное, библиотечное волонтерство);

- событийное волонтерство (в том числе в музейных, межмузейных, межведомственных, межсекторных проектах);

- волонтерство в сфере сохранения объектов культурного наследия;

- волонтерство профессионалов - деятелей культуры и искусства.

Мы видим разделение направлений, связанное с объектом приложения добровольной помощи. Вместе с тем объекты волонтерской деятельности в диахронном аспекте, аспекте отстояния от культурного явления, можно рассмотреть в дихотомии создания культурных ценностей - сохранения и актуализации культурного наследия, как волонтерство в современных культуротворческих и художественных практиках (собственно волонтерство культуры, арт-волонтерство) и волонтерство, связанное с сохранением, популяризацией и актуализацией ранее созданных культурных ценностей (волонтерство наследия).

Проект «Волонтеры наследия» вычленен, в связи со спецификой наполнения понятия и видов деятельности, в рамках программы «Волонтеры культуры» национального проекта «Культура». Существует устойчивая тенденция к расширению понимания наследия, поскольку данная ценностная категория включает в себя накопленное богатство культурного опыта человечества, и объем понятия находится в непосредственной зависимости от существующего уровня развития культуры. Согласно определению Большой Российской энциклопедии музеев, частных собраний и коллекций, «культурное наследие - совокупность связей, отношений и результатов духовной деятельности прошлых исторических эпох», а также «совокупность объектов окружающего человека мира, признаваемых на основе культурного опыта человечества и его предпочтений культурными ценностями» [5, с. 312]. Российская музейная энциклопедия рассматривает уже в единстве культурное и природное наследие как «совокупность объектов культуры и природы, отражающих этапы развития общества и природы и осознаваемых социумом как ценности, подлежащие сохранению и актуализации» [6].

Наиболее широкое распространение получило представление о культурном наследии как целостном явлении, обладающем информационным потенциалом, необходимым для передачи будущим поколениям, «системе материальных и интеллектуально-духовных ценностей, созданных и сбереженных предыдущими поколениями и представляющих исключительную важность для сохранения культурного и природного генофонда Земли и для ее дальнейшего развития» [7], предложенное Ю. А. Ведениным. Появившись еще в 70-е гг. XX в. в результате деятельности ЮНЕСКО в «Конвенции об охране всемирного культурного и природного наследия» 1972 г. концепция «общего всемирного наследия», которое было признано «выдающейся универсальной ценностью», сегодня стала еще более глобальной и включает в себя многообразие проявлений. Конвенция обозначила развившуюся позднее концепцию взаимозависимости культурного и природного наследия: культурная самобытность и достижения разных народов были подкреплены взаимодействием с окружающей средой, в которой они жили. Экологический подход проявился за рубежом в масштабной распространении заповедных территорий, национальных парков, природных парков и экомузеев, в нашей стране в 1990-е гг. - в появлении такой формы сохранения наследия, как уникальные историко-культурные и природные территории, существующие в вышеупомянутых формах, и наиболее распространенной форме историко-культурных и природных музеев-заповедников.

На рубеже веков понятия «историческое поселение», «достопримечательное место» широко вошли в теорию и практику, нормативную базу сохранения наследия. Распространение средового подхода к сохранению наследия привело к тому, что сегодня объектами сохранения стали исторические улицы, кварталы, исторические поселения, исторические центры городов и даже целые города. Появившийся еще в середине XX в. термин «историческое поселение» получил широкое распространение. СанктПетербург - крупнейший объект культурного наследия. Номинация объекта ЮНЕСКО «Исторический центр Санкт-Петербурга и связанные с ним группы памятников» расположена в двух субъектах Российской Федерации (Санкт-Петербург и Ленинградская область), включает 36 компонентов и 86 элементов, границы всего объекта охватывают территории свыше 23 тыс. га, поэтому эпитет «музей под открытым небом» город получил заслуженно.

Необходимость сохранения культурного разнообразия повлекла за собой понимание важности нематериального культурного наследия, закрепленное в 2003 г. в «Международной конвенции об охране нематериального культурного наследия», и его документирования. Таким образом, в 2000-е гг. в круг объектов наследия включились такие признанные мировым сообществом феномены, как подводное наследие, нематериальное наследие, цифровое наследие. 
Видовое изменение сохраняемого наследия повлекло и соответствующие изменения занимающихся им институций. Помимо устоявшихся культурных форм, таких как музеи, архивы, библиотеки, заповедники, национальные парки, появились и другие: УИКТ, сайт-музеи, средовые музеи, экомузеи, живые музеи, экономузеи, виртуальные музеи и архивы, разнообразные учреждения музейного типа, совмещающие функции музея и другого учреждения. Сложность форматирования различных объектов культурного наследия и управления ими вызывает к жизни и неформализованные инициативы: некоммерческие организации (НКО), волонтерские движения, группы, индивидуальные инициативы.

На сегодняшний день можно говорить о системном представлении о наследии как транслируемой системе ценностей, отражающих публичную память, накопленном человечеством опыте, который должен актуализироваться, помогать решать современные задачи и формировать контур будущего. Именно с точки зрения общности процессов сбора, сохранения, изучения и репрезентации самых различных видов наследия можно рассмотреть и вопросы волонтерства наследия, не замыкаясь в институциональном осмыслении только одного из социокультурных институтов. Размышления о единстве процессов формирования институтов публичной памяти, одним из которых является музей, наряду с архивом, библиотекой, которое должно стать объектом осмысления единой науки о наследии - «наследиеведение» или «heritology», «мнемософия» с 1982 г. продвигает Томислав Шола [8].

Активные социокультурные, экономические и политические преобразования в обществе требуют осмысления и обращения к ценностям, признанным, отобранным обществом в качестве значимых. Это и материальное, движимое и недвижимое, наследие, а также нематериальное наследие. Наблюдается процесс изменения отношения общества к своему культурному наследию, пусть и не слишком быстрый, последовательно поддерживаемый, особенно в плане самодеятельных, проектных, волонтерских инициатив, международными и национальными организациями. Широкое понятие «волонтер наследия» призвано объединить всех лиц, отдающих безвозмездно свое время и силы для поддержания явлений публичной памяти и ее институтов, деятельности по сохранению и актуализации наследия: волонтеров библиотек и архивов, музеев и парков, волонтеров поисковых объединений и воинских захоронений, волонтеров акций памяти и фестивалей истори- ческой реконструкции и многих других. Важной и специфичной областью является волонтерская деятельность, нацеленная на популяризацию, конкретные действия по поддержанию в порядке, обустройства территории, ухода за историческими зданиями и памятниками, ремонта, и в разрешенных законом пределах консервации реставрации объектов культурного и природного наследия, а также культурных ландшафтов. Участника данной волонтерской деятельности зачастую определяют как «волонтера наследия», характеризуя его в качестве добровольца, принимающего участие в реализации культурных инициатив по сохранению и популяризации объектов культурного наследия, хотя точнее было бы определение «волонтер в сфере сохранения объектов культурного наследия». Повышение интереса к данному виду волонтерской деятельности государства в лице федеральных и региональных органов, отвечающих за выработку политики в сфере сохранения культурного наследия, активизация деятельности ВООПИиК и появление новых общественных организаций и движений привели к осмыслению практики в публикациях последних лет [9].

Понятие «музейный волонтер», несомненно, входит в широкое понятие «волонтер наследия». Осмысление феномена музея, изменение и расширение понятия самого музея и его функций напрямую связаны с многогранной практикой музейной деятельности, введением в нее новых явлений, более тесным взаимодействием со сферой сохранения культурного и природного наследия в целом. Культурное наследие и музей - взаимосвязанные и взаимообусловленные понятия. Функция сохранения, трансляции и актуализации культурного наследия в ходе исторического развития лежали на разных институтах социальной памяти, однако музей играл в этом процессе ведущую роль, постепенно переходя от ориентации на музейные ценности, выполнявшие представительские функции - предметы, уникальные движимые объекты культурного наследия - к репрезентативным и все более масштабным объектам, явлениям и процессам духовной жизни общества - недвижимым и нематериальным объектам наследия. Поэтому музейный волонтер - это человек, непосредственно связанный с практиками сохранения, популяризации и интерпретации наследия через институциональную форму музея. Сегодня музейные волонтеры выполняют многообразие функций: помогают в организации массовых мероприятий, встречают и консультируют посетителей, готовят и проводят экскурсии и арт-медиации, ведут соцсети и пишут информационные посты для сайта, и даже помогают 
в исследованиях и работе с музейными фондами [10]. Тем не менее не все отечественные музеи в полной мере осознают и используют возможности, предоставляемые добровольными помощниками. В американских музеях, имеющих глубокие традиции волонтерской деятельности в музеях, волонтеры работают более 1 млн часов в неделю, на одного штатного сотрудника в среднем приходится 6 волонтеров, причем в крупных музеях эта пропорция составляет 1:2, а в небольших - 1:18. [11]. Ориентируясь на зарубежный опыт, российские музеи расширяют работу с волонтерами, создают внутренние структуры и устойчивые взаимосвязи, обобщают опыт и делятся им. Большинство отечественных музеев имеет опыт привлечения волонтеров на отдельные проекты и события. Некоторые уже создали свои постоянные волонтерские сообщества, содействующие решению повседневных задач.

Ряд музеев имеет опыт работы с корпоративными волонтерами и волонтерами pro bono - профессионалами, предоставляющими безвозмездную помощь музеям в решении задач, непосредственно связанных с их сферой деятельности (юристами, экономистами, переводчиками и т. д.).

Однако волонтерство - это не только бесплатная помощь музеям, это мощный ресурс развития музея и самого волонтера, общества в целом. Опыт зарубежных и отечественных музеев подтверждает эффективность музейного волонтерства в установлении диалога с обществом, реализации миссии музеев. Участие в добровольной работе музея - реализация музейных программ в поддержку миссии музея в обществе. Волонтер участвует в разработке музейных инициатив, которые отвечают потребностям сообщества, представленного добровольцем. Волонтеры предоставляют имеющиеся у них знания и опыт, чтобы помочь развитию музея, повысить информированность сообщества о его наследии и роли музеев в его сохранении.

Комплексный подход к осмыслению отношений музейной организации и волонтеров открывает возможность углубления взаимопонимания между музеем и сообществом через добровольца (добровольцев). Волонтерство становится одним из актуальных способов взаимодействия музейной организации и социума. По словам М. Б. Гнедовского, «волонтеры - это особая категория "возвратных" посетителей, которые регулярно приходят в музей и активно включаются в его деятельность» $[12$, с. 5].

В последние годы стала популярна концепция «третьего места», которая говорит о том, что учреждения культуры, общественные объединения начинают играть не только научно-просветительскую роль, но во многом становятся «третьим» после дома и работы местом, где человек проводит свою жизнь, где он может обрести свою социальность, найти новых друзей, просто почувствовать себя нужным, и музей может стать именно таким местом. Стратегия волонтерского движения, основанная на осознанном единении, понимании ответственности за другого человека и за культуру, на ощущении ценности человеческой жизни и значимости истории, традиций может не только найти ответы на вопросы внутри социума, но и преобразовать имидж и уровень осмысления музея людьми в самых отдаленных уголках мира.

В быстро меняющемся мире современности эффективное регулирование в области организации волонтерства, базирующееся на понимании задач данного типа взаимодействия, поможет, на наш взгляд, объединиться для создания новых интересных проектов в рамках культурного волонтерства, повысит энтузиазм, откроет новые грани культурной коммуникации.

\section{Список литературы}

1. Федеральный закон от 11 авг. 1995 г. № 135-Ф3 «О благотворительной деятельности и добровольчестве (волонтерстве)» (с изм. и доп.) // Гарант. Ру: информ.-правовой портал. URL: https://base.garant.ru/104232/ (дата обращения: 27.04.2021).

2. Распоряжение Правительства РФ от 27 дек. 2018 г. № 2950-р. «Об утверждении Концепции развития добровольчества (волонтерства) в России до 2025» // Правительство России: сайт. URL: http://government.ru/ docs/35231/ (дата обращения: 27.04.2021).

3. Программа «Волонтеры культуры» // Министерство культуры Российской Федерации: сайт. URL: https://culture. gov.ru/about/national-project/creative-people/volunteers/ (дата обращения: 27.04.2021).

4. Горлова Н. И., Маковецкая Д. Т. Сборник волонтерских практик в сфере культуры: метод. рекомендации. Москва, 2019. 124 с.

5. Культурное наследие // Большая Российская энциклопедия музеев, частных собраний и коллекций. М.: Прогресс: РИПОЛ классик, 2009. С. 312.

6. Культурное и природное наследие // Российская музейная энциклопедия. URL: http://museum.ru/rme/ dictionary.asp?85 (дата обращения: 27.04.2021).

7. Веденин Ю. А. Современные проблемы сохранения наследия // Культурное и природное наследие в региональной политике: тез. докл. республ. науч.-практ. конф. Ставрополь, 1997. С. 4-9.

8. Шола Т. С. Мнемософия: эссе о науке публ. памяти / ИКОМ России; ГМЗ «Ростовский Кремль». Ростов Великий, 2017. 320 c. 


\section{Ю. В. Зиновьева}

9. Воропаева М. Д., Горлова Н. И., Губина А. В. и др. Анализ практики привлечения добровольцев к сохранению культурного наследия (на примере России, Великобритании и Франции). М.: ВООПИиК, 2020. 309 с.

10. Актуальные практики музейного волонтерства: сборник. М.: Мосгортур, 2020. 92 с.

11. Merrit E. Volunteers and Museum Labor // American Alliance of Museums: website. URL: https://www.aam-us. org/2016/10/18/ volunteers-and-museum-labor (дата обращения: 27.04.2021).

12. Гнедовский М. Б. Музейные волонтеры: кто они? // Волонтеры в музее / отв. ред.-сост. И. А. Гринько. М.: Мосгортур; Благотворит. фонд В. Потанина, 2019. С. 4-5.

\section{References}

1. Federal law of Aug. 11.1995 N 135-FZ «On charity and volunteering (volunteering)» (rev. and add.). Garant.Ru: inform.-legal portal. URL: https://base.garant.ru/5426825/ (accessed: Apr. 27.2021) (in Russ.).

2. Order of the Government of the Russian Federation of Dec. 27.2018 N 2950-r. «On the approval of the Concept for the development of volunteering (volunteering) in Russia until 2025». Government of Russia: website. URL: http://government.ru/docs/35231/ (accessed: Apr. 27.2021) (in Russ.).

3. Program «Volunteers of Culture». Ministry of Culture of the Russian Federation: website. URL: https://culture.gov.ru/ about/national-project/creative-people/volunteers/ (accessed: Apr.04.2021) (in Russ.).
4. Gorlova N. I., Makovetskaya D. T. Collection of volunteer practices in the field of culture: method. recommendations. Moscow, 2019.124) (in Russ.).

5. Cultural heritage. Great Russian Encyclopedia of Museums, Private Collections and Collections. M.: Progress: RIPOL classic, 2009.312 (in Russ.).

6. Cultural and natural heritage. Russian Museum Encyclopedia. URL: http://museum.ru/rme/dictionary. asp?85 (accessed: Apr. 27.2021) (in Russ.).

7. Vedenin Yu. A. Modern problems of heritage conservation. Cultural and natural heritage in regional politics: abstr. report republ. sci.-practical conf. Stavropol, 1997. 4-9 (in Russ.).

8. Shola T. S. Mnemosophy: an essay on science publical memory / ICOM Russia; State Museum-Reserve «Rostov Kremlin». Rostov Veliky, 2017. 320 (in Russ.).

9. Voropaeva M. D., Gorlova N. I., Gubina A. V. et al. Analysis of the practice of attracting volunteers to the preservation of cultural heritage (on the example of Russia, Great Britain and France). M.: All-Russ. Society for the Protection of Historical and Cultural Monuments, 2020.309 (in Russ.).

10. Actual practices of museum volunteering: collection. Moscow: Mosgortur, 2020.92 (in Russ.).

11. Merrit E. Volunteers and Museum Labor. American Alliance of Museums: website. URL: https://www.aam-us. org/2016/10/18/ volunteers-and-museum-labor (accessed: Apr. 27.2021).

12. Gnedovsky M. B. Museum volunteers: who are they? Volunteers in the museum / comp. Grin'ko I. A. M.: Mosgortur; V. Potanin Foundation, 2019. 4-5 (in Russ.). 